\title{
As percepções de agricultores familiares sobre transição agroecológica em uma cooperativa agropecuária no Rio Grande do Sul
}

\section{Perceptions of family farmers about agroecological transition in an agricultural cooperative in Rio Grande do Sul}

\begin{abstract}
Joice Zagna Valent ${ }^{*}$
Resumo: Objetivou-se descrever as percepções dos agricultores familiares de uma cooperativa agropecuária do Rio Grande do Sul sobre as implicações causadas pela mudança de sistema produtivo: da agricultura convencional para a produção agroecológica de alimentos. Para embasar o trabalho foram usadas as teorias da mudança, agroecologia, cooperativismo e agricultura familiar. O estudo classifica-se como uma pesquisa exploratória e descritiva, com tratamento qualitativo dos dados, por meio da análise de conteúdo. Foram realizadas entrevistas com os 39 agricultores. Observa-se que nas percepções individuais os assuntos mais referenciados foram: conhecimento, comunicação e planejamento; resistência e mudança; saúde e renda. $\mathrm{O}$ estudo demonstrou que a mudança de sistema produtivo é lenta, porém importante para os agricultores. Contudo, o comprometimento de todos na transição agroecológica foi essencial para o bom desempenho organizacional.
\end{abstract}

Palavras-chave: Agricultura familiar; Agroecologia; Cooperativismo; Mudança.

Abstract: The aim of this article was describes perceptions of family farmers of a agricultural cooperative from Rio Grande do Sul about implications caused by the production system changing: from conventional to agroecological food production. To support the work, were used the Theories of change, agroecology, cooperatives and family farming. The study is classified as an exploratory and descriptive research with qualitative treatment of the data, through content analysis. Interviews were conducted with the 39 farmers. Individual perceptions in the most referenced topics were: knowledge, communication and planning; resistance and change, health and income. The study showed that the change in the productive system is slow, but important for farmers. However, the involvement of everyone in the agroecological transition was essential for good organizational performance.

Keywords: Family farming; Agroecology; Cooperativism; Change.

*Autor para correspondência

Recebido para publicação em 06/04/2016; aprovado em 07/06/2017

*Doutoranda em Agronegócio, Universidade Federal do Rio Grande do Sul, Porto Alegre - RS; (51) 3308-6586; jzvalent@ gmail.com 


\section{INTRODUÇÃO}

A demanda por alimentos agroecológicos requer mudanças em sistemas produtivos, focadas em práticas sustentáveis. Para Lima et al. (2014), um novo modelo de agricultura deve ser pautado em bases ecológicas, envolvendo atividades agrícolas que gerem renda e, ao mesmo tempo, preservem os recursos naturais. Azevedo et al. (2011) afirmam que um modelo agrícola sustentável torna-se instrumento de promoção de valores sociais e de qualidade de vida no meio rural, com repercussões igualmente importantes no meio urbano. Nesse cenário, as transformações rurais estimulam as mudanças.

A partir disso, a agroecologia passa a ser um novo caminho para a agricultura de base ecológica e sustentável, construindo novos conhecimentos (JESUS et al., 2011). Nesse contexto, as cooperativas agropecuárias podem auxiliar no aprendizado de novas formas de manejo na agricultura, bem como na comercialização dos produtos. A opção pela linha cooperativista se impõe, porque o trabalho realizado sob essa concepção possibilita agregar mais pessoas em torno de um propósito comum. Entre as cooperativas agropecuárias abrem-se espaços mais sensíveis a mudanças, quer seja pelo envolvimento das pessoas, ou pelos interesses cooperados.

As organizações cooperativas são estruturadas no sentido de congregar as pessoas em torno de um ideal comum (PINHO, 1967). Assim, o cooperativismo sustenta-se sobre a ideia de mutualidade, união de esforços, solidariedade, democracia e autogestão (BUTTENBENDER, 2010). As pessoas motivadas para a cooperação tornam-se mais flexíveis e menos resistentes às mudanças, contribuindo de modo efetivo para o desenvolvimento do trabalho conjunto. Essa condição de abertura ao novo é reforçada pela participação democrática, uma postura embasada na construção do "saber cooperar" (FERREIRA; AMODEO, 2008; SCHNEIDER, 2003). Costa, Amorim Júnior e Silva (2015), salientam que além da cooperação, os sócios têm que possuir capacidades administrativas e operacionais para a gestão das cooperativas.

Nesse sentido, as cooperativas agropecuárias podem ser instrumentos de apoio para a transição agroecológica. Esta é definida como um conjunto de conhecimentos e técnicas que se desenvolvem a partir de agricultores e de seus processos de experimentação. Por isso, enfatiza a importância de comunidades locais inovarem nos processos produtivos, por meio de experimentos transmitidos de agricultor para agricultor (ALTIERI, 2012). O mesmo autor argumenta que as práticas cooperativas promovem mudanças na agricultura, aproveitando oportunidades emergentes, sobretudo, aquelas aliadas ao desenvolvimento rural sustentável.

Diante do exposto, o presente estudo teve como objetivo descrever as percepções dos agricultores familiares durante a transição agroecológica de uma cooperativa agropecuária, localizada no Estado do Rio Grande do Sul.

\section{MATERIAL E MÉTODOS}

O trabalho foi realizado em uma Cooperativa localizada no município de Boqueirão do Leão, na região dos Vales, mesorregião Centro Oriental Riograndense, microrregião de Lajeado-Estrela, com latitude $29^{\circ} 18^{\prime} 14$ "S e longitude 52²5'46"O (IBGE, 2013), (Figura 1).
Figura 1. Município de Boqueirão do Leão, Estado do Rio Grande do Sul

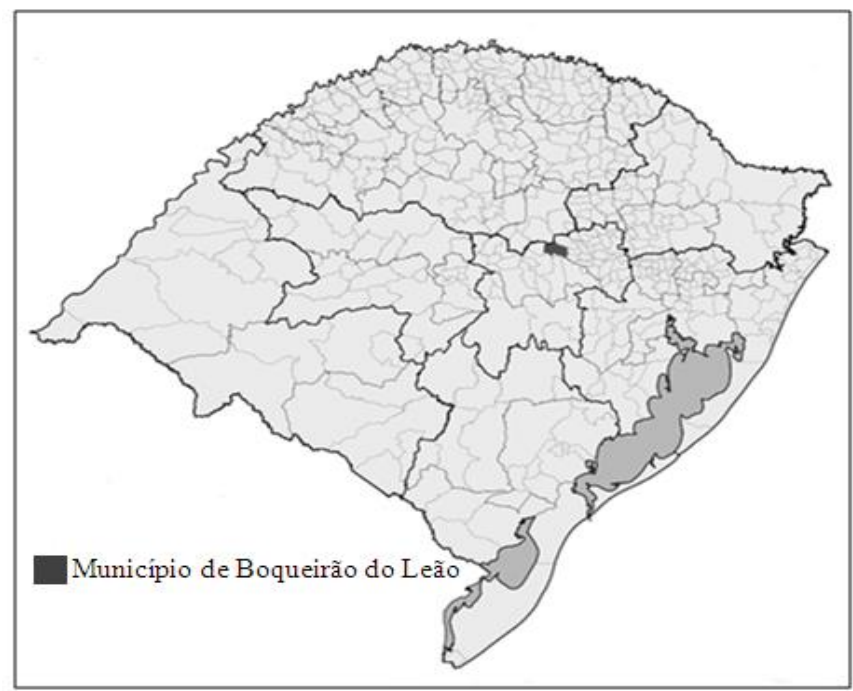

Fonte: Adaptado do Instituto Brasileiro de Geografia e Estatística IBGE (2010).

O município de Boqueirão do Leão possui cerca de 8.000 habitantes e área de $265,5 \mathrm{~km}^{2}$ (FEE, 2011). No ano de 1987 tornou-se independente do município de Lajeado, conseguindo, assim, sua emancipação.

O público-alvo do presente estudo foi os 39 agricultores cooperados. O conjunto designa a totalidade de indivíduos que possuem as mesmas características. Para que haja uma clara definição das unidades que formam a população é necessária a especificação de três elementos: uma característica em comum, localização temporal e localização geográfica (UFPR, 2009). A Cooperativa é composta por agricultores familiares, sendo a maioria desses, residentes no município de Boqueirão do Leão e alguns, em municípios vizinhos. Fundada em nove de dezembro de 2010, a Cooperativa reunia um grupo de 29 agricultores do município de Boqueirão do Leão.

No início de suas atividades, a Cooperativa fornecia alimentos da agricultura familiar para a alimentação escolar no município. Tanto o fornecimento de notas fiscais para a Prefeitura como a preocupação com a segurança alimentar obrigaram a formalização da associação. Pode-se dizer que a diversificação sustentável das propriedades de agricultores familiares, voltada apenas para pequenos produtores rurais, também impulsionou essa legalização.

Os precursores da Cooperativa se preocuparam sobremodo com o desenvolvimento econômico e social, tendo em vista que os cooperados eram pequenos agricultores. Por meio de reforço participativo e de apoio municipal, eles promoveram a inclusão desses produtores agrícolas.

Atualmente, a Cooperativa conta com 39 cooperados. Ela atende à demanda de produtos para o preparo da alimentação escolar em 15 escolas municipais e seis escolas estaduais. Ainda fornece cerca de 50 produtos para comercialização, inclusive em feiras de outros municípios. Em função disso, a cooperativa iniciou uma mudança no sistema de produção. Em 2012, os agricultores cooperados iniciaram o processo de transição agroecológica, visando a uma vida mais saudável, ao incremento da renda familiar e ao adequado manejo de agroecossistemas. 
Tratando-se de uma organização cooperativa, esse estudo é caracterizado como pesquisa social empírica, do tipo aplicada, porque seu foco está no setor primário da economia. A pesquisa aplicada é aquela que espera obter melhoria ou progresso de algum processo ou atividade, ou seja, visa o alcance de resultados práticos com intervenção no meio social (DORNELLES, 2006).

A presente pesquisa é classificada como exploratória e descritiva. Rodrigues (2007) define a pesquisa exploratória como a destinada a reconhecer a natureza do fenômeno, é uma operação de reconhecimento, uma sondagem destinada à aproximação em face do desconhecido. A pesquisa descritiva observa, registra, analisa e correlaciona fatos ou fenômenos (variáveis) sem manipulá-los. O estudo é censitário, pois entrevistou todos os agricultores cooperados. A coleta de dados foi primária e secundária. A última porque foi feita pesquisa em documentos da Cooperativa. A análise de tratamento de dados foi qualitativa. Na primeira fase do trabalho ocorreu a pesquisa documental (dossiê, estatuto, diagnóstico rural participativo e relatórios cadastrais) para obter informações sobre a Cooperativa.

A coleta de dados primários ocorreu na segunda fase do estudo. Nessa etapa, os cooperados foram entrevistados para posterior análise das respostas. $\mathrm{O}$ instrumento utilizado para coleta de dados foi um formulário de entrevista semiestruturado. O formulário é destinado à coleta de dados resultantes de interrogações. Considerando a relevância da mudança de sistema produtivo, os agricultores foram entrevistados na forma de comunicação verbal-oral, por meio de entrevista pessoal e em situação de mensuração formalizada. Em ambos, o preenchimento é feito pelo próprio investigador, por meio de interrogatório para recolher dados para a pesquisa.

A análise utilizada foi de forma qualitativa. O trabalho investigou dados de natureza subjetiva, por meio de percepções e atitudes dos entrevistados sobre transição agroecológica.

Nesse trabalho a percepção foi definida como a função cerebral que permite ao indivíduo organizar e interpretar as impressões sensoriais, de forma a atribuir significado ao meio, a partir de um histórico de vivências passadas. O seu processo consiste na aquisição, interpretação, seleção e organização das informações obtidas (MARTINS, 2011).

O material para análise foi preparado da seguinte forma: as perguntas abertas foram transcritas na íntegra. Definido o corpus de 39 entrevistas, iniciou-se a pré análise para sistematizar as ideias iniciais das respostas. Essa fase consistiu em uma leitura flutuante do material. Com isso, foi possível tomar conhecimento da estrutura das narrativas e conceber as primeiras impressões. Segundo a regra de exaustividade, as entrevistas foram analisadas em sua totalidade. Dessa forma, mantiveram graus de homogeneidade e pertinência ao tema (BARDIN 2011).

\section{RESULTADOS E DISCUSSÃO}

A tomada de decisão nas organizações depende cada vez mais de conhecimentos e competências e deve ser mais descentralizada, ou seja, todos devem participar (LAUDON; LAUDON, 2007).

A dinâmica da inovação no setor agrícola é impulsionada por uma combinação de geração de conhecimento público e capacidade de aprendizagem dos agentes envolvidos no processo de adoção de tecnologia. A aprendizagem dos produtores, por meio do aumento da capacidade de absorção, auxilia na gestão de novos conhecimentos. Nesse sentido, o ambiente organizacional deve fornecer conhecimentos adequados para explorar o setor produtivo, mas cabe aos agricultores investir na sua formação, a fim de entender e aproveitar melhor as oportunidades, reduzindo a dependência de insumos externos (ALVES, 2012).

Para Mota et al (2014), o processo de globalização da degradação socioambiental tem imposto conhecimento científico que absorva conceitos ecológicos visando à sustentabilidade. Portanto, o saber ambiental está num processo de construção. Assim, a interdisciplinaridade implica na integração de processos naturais e sociais de diferentes ordens.

Nesse contexto, alguns cooperados demonstraram ciência de que o conhecimento é importante na transição agroecológica (Quadro 1).

Quadro 1. Assertivas sobre a importância de conhecimentos a respeito da transição agroecológica de sócios de cooperativa agropecuária em Boqueirão do Leão, Rio Grande do Sul

Nas reuniões adquiri conhecimento da produção orgânica (E17).

Futuro melhor e absorção de conhecimento (E34).

Conhecimento e futuro melhor. Planejamos para plantar só verdura orgânica (E16).

É boa, porque sabe que vai dar certo. Muita gente visita a propriedade para saber como é a produção orgânica e a família fica satisfeita, pois passa conhecimento para outras pessoas. O começo não é fácil, mas tem que buscar conhecimento (E38).

Fazer com carinho, se fizer errado tem que consertar, pois é assim que se aprende (E9).

Huang (2013) afirma que para haver troca de conhecimento, a comunicação verbal é imprescindível. É preocupação da gestão ter um sistema de comunicação canalizador de conhecimentos e informações para os pontos decisórios apropriados. A comunicação também é considerada parte da política de desenvolvimento de recursos humanos, mas com determinada independência (ALVES, 2012).

Nesse sentido, dois cooperados reclamaram que, muitas vezes, não tem clareza e objetividade nas informações repassadas pela diretoria. Eles afirmaram que é necessário haver mais comunicação (Quadro 2).

Quadro 2. Afirmação sobre comunicação no processo de transição de sócios de cooperativa agropecuária em Boqueirão do Leão, Rio Grande do Sul

Falta comunicação (E4 e E18).

A construção de novos conhecimentos ocorre pela divulgação de fatos e o que permite esse processo é a comunicação. A carência desta provoca a perda de foco da decisão e/ou ação, distorcendo as informações divulgadas 
com prejuízo de várias ordens. Portanto, a comunicação influencia na eficiência e eficácia dos sistemas. A comunicação é conhecimento codificado, que pode ser expresso de forma sistematizada, transmitido, difundindo e ampliado (VALENT, 2013).

Nesse contexto, as oscilações do ambiente podem ser previstas, pois interferências do meio podem ocorrer no planejamento. Por isso ele deve ser flexível. Os aspectos internos da propriedade e as variáveis do ambiente devem ser conhecidos, para agir com maior certeza. Assim, é importante conhecer quais são os objetivos do empreendimento rural para estabelecer estratégias. É necessário planejar antes de agir. Para tanto, torna-se imprescindível que os agricultores conheçam como ocorre a transição e expressem suas percepções sobre planejamento (Quadro 3).

Quadro 3. Percepções dos agricultores sobre planejamento na transição agroecológica em cooperativa agropecuária em Boqueirão do Leão, Rio Grande do Sul

Tem que ter consciência que imprevistos podem acontecer no percurso (E19).

Deve planejar sempre para não fazer errado. É só fazendo que se aprende (E9).

É uma coisa boa, mas tem que ser organizado para ter futuro (E15).

Tem que ter organização para a Cooperativa obter sucesso e todos os cooperados lucrarem com isso (E24).

Falta de organização - quem vai plantar o quê $e$ a quantidade que cada um vai plantar (E4).

Os agricultores devem estar dispostos a mudar (E 13).

Para que a mudança tenha sucesso deve haver confiança e garantia de que algo importante será conquistado. A efetiva comunicação e esclarecimento da situação devem ser estratégias para promover o envolvimento dos participantes (JACOBSEN; RODRIGUES, 2002). Kotter (1999) relata que uma mudança planejada pode se tornar um processo de melhoria contínua.

A resistência é uma característica da mudança, pois tudo que é novo pode causar insegurança e dúvidas. No entanto, essa resistência pode ser minimizada com cooperação. Como afirma Pinho (1967), o movimento cooperativo congrega as pessoas em torno de um ideal comum. Nesse ambiente, as pessoas são motivadas e se tornam menos resistentes às mudanças e, em consequência, contribuem para sua efetivação. Na transição agroecológica da Cooperativa, houve pouca resistência (Quadro 4).

Quadro 4. Assertiva sobre a ausência de resistência à mudança de sistema produtivo em cooperativa agropecuária em Boqueirão do Leão, Rio Grande do Sul

Sem dificuldades e resistência (E17).

Verifica-se que mesmo tratando-se de uma situação nova, a vontade de mudar era maior. Entretanto, outras alegações apareceram em relação à resistência e também à associação que os pais fazem entre a transição agroecológica e a permanência dos filhos no meio rural (Quadro 5).
Quadro 5. Afirmações sobre a relação de transição agroecológica com a permanência no campo de sócios de cooperativa agropecuária em Boqueirão do Leão, Rio Grande do Sul

Os mais velhos são mais resistentes (E12).

Os cooperados mais idosos são resistentes, mas cabe aos jovens mostrar a importância disso (E36).

Não é fácil, os mais jovens mudam com mais facilidade. Para os mais velhos, que já trabalharam muito tempo com tabaco, é mais difícil (E32).

A maioria dos cooperados é jovem e devem aproveitar essas oportunidades (E37).

O jovem não fica no interior, precisa de mais incentivo por parte das prefeituras e mesmo assim não fica (E10).

Podia ter ocorrido há mais de 20 anos para os filhos terem ficado em casa (E7).

A resistência é um fator presente, principalmente, nas pessoas com idade mais avançada. Isso pode ser em função de aspectos sociais, tais como rejeição às coisas novas, valores já internalizados e conformidade às normas existentes (JACOBSEN; RODRIGUES, 2002). A aposta para que a mudança tenha êxito está nos jovens. Nos relatos acima, eles são citados como pessoas que realmente têm capacidade de mudar o meio onde vivem, aproveitando as oportunidades que surgem. Isso se legitima, pois os jovens são mais comunicativos, engajados, possuem mais habilidade com tecnologias e suas convicções culturais ainda não estão bem estruturadas.

Uma barreira impeditiva de permanência dos jovens no campo é a falta de incentivo das prefeituras. As políticas públicas são falhas ou inexistentes. Um cooperado acredita que se a transição agroecológica tivesse ocorrido há 20 anos, os filhos teriam ficado em casa. Para alguns, a mudança associa-se com condições melhores de vida no meio rural, com alimentação saudável e uma renda maior para a família.

Nesse contexto, cada agricultor cooperado tem objetivos próprios para sua família e percebe a transição agroecológica de forma diferente (Quadro 6).

Quadro 6. Percepções das famílias cooperadas sobre o processo de transição agroecológica nas propriedades rurais em Boqueirão do Leão, Rio Grande do Sul

Processo demorado e lento. A conscientização, persistência, perseverança, trabalho em equipe e motivação devem estar presentes sempre. Tenho vontade para fazer tudo. É uma mudança cultural (E2).

A mudança foi vantajosa quando todos assumiram o processo. Processo lento e foram se atualizando aos poucos. Têm atenção maior da assistência (E37).

Todos devem trabalhar pelo mesmo objetivo, mas é um processo lento (E25).

É um processo lento, todos devem cooperar (E13).

É lenta, tem que ir devagar. Toda mudança muda (E19). 
Lenta, uma mudança é difícil. É importante, pois se trata da segurança alimentar (E4).

É mais lenta, mas pode mudar a renda das pessoas. A diversificação - opção de trabalhar com outros produtos tem consumidor específico (E35).

Lenta, mas tenta se planejar, procurar melhor preço para os cooperados (E20).

Lenta. Tem que ter garantia de preço para investir. É complicado entrar em consenso para agradar a todos. Depende de todos para dar certo (E30).

Começo de algo bom, fraco, devagar, com política no meio, mas bom (E21).

Aos poucos se avança com os pés no chão. Quando tiver o selo a renda vai aumentar e com união pode transformar o município em uma rota turística. Tem que organizar para manter a cooperação com sucesso (E23).

Trabalho em longo prazo tem que mudar a consciência e percepção. Isso muda, além de valores econômicos, a saúde e a vida social. Porque agora consome produto orgânico e muda a vida da família e modo de pensar de cada um. No início é tudo mais caro, mas depois os insumos usados na produção se tornam mais baratos e o valor de venda é maior (E39).

Não se pode esquecer que, apesar de essenciais, as mudanças exigem dos gestores esforços extras, na medida em que trazem consigo outras modificações dentro da organização. Afinal, a mudança é naturalmente um processo complexo e lento, uma vez que seu gerenciamento implica em mudar os hábitos, os modelos de comportamento e também as atitudes das pessoas, no que tange à maneira de executar as suas funções.

Alguns dos objetivos que induzem às mudanças dentro das organizações são para melhorar: o produto em termo de qualidade e extensão de função, as relações humanas dentro da organização e a capacidade de organização, para resolver problemas e atender as mudanças no mercado (JUDSON, 1976).

Percebe-se que as promessas feitas para o sucesso da implementação de mudanças e do controle dos níveis de resistência exigem, no mínimo, a observância de determinados fatores. Além da necessidade de se desenvolver determinadas habilidades administrativas, por parte dos responsáveis, é preciso, também, o esclarecimento e a preparação das pessoas envolvidas. Adicionalmente, algumas características do processo de mudança não podem ser esquecidas, tais como: a resistência às mudanças é natural; há a necessidade inexorável de descongelar os padrões de comportamento atuais; e a tendência das pessoas é de continuar fazendo as coisas como sempre (JACOBSEN; RODRIGUES, 2002).

Devido a diferenças na forma como os proprietários conduzem suas unidades produtivas ou como resultado de diferenças de circunstâncias pessoais, a tomada de decisão coletiva é o resultado da heterogeneidade de interesses entre as pessoas. Esse resultado deve maximizar o bem estar dos proprietários como um grupo (CHADDAD; ILIOPOULOS, 2013).

Pelo visto, os fatores que melhor representam essa heterogeneidade são saúde e renda. A transição agroecológica está ligada às questões de saúde e ao bem-estar do produtor e de sua família, e, principalmente, em torno da preocupação com a possibilidade de garantir maior rendimento econômico, permitido por um mercado em rápido crescimento (LIMA et al., 2014). Desse modo, os empreendimentos cooperativos estão inseridos no fluxo real de produção de bens e serviços, articulando-se com os demais agentes (BEGNIS et al., 2014). No quadro 7 observa-se as percepções sobre a transição agroecológica dos cooperados.

Quadro 7. Percepções sobre saúde e renda com a transição agroecológica de sócios de cooperativa agropecuária em Boqueirão do Leão, Rio Grande do Sul

É uma coisa boa, pois preserva a saúde e sabe o que come (E6).

Prolongação da vida. Poupança de saúde (E26).

Não usar agrotóxico é saber o que está comendo, que é saúde, que é uma coisa boa (E3).

Boa. Pode proporcionar uma saúde melhor e mais renda (E31).

Faço o que gosto e acredito, possibilitando a aprendizagem de outras pessoas, alimentação saudável, com prazer e ganhando dinheiro (E1).

Pode ser lucrativo. Deve dar lucro para continuar (E10).

Procurar mercados novos para ter possibilidade de vender bastante (E23).

Tem dois lados: quando o preço é bom a empolgação é geral. Ao contrário não. Deve haver cooperação (E28).

Com a certificação terá maior valorização do produto, maior reconhecimento, melhoria na vida de todos e oportuniza e estimula os jovens, por meio da diversificação, à permanência no campo (E29).

O principal produto orgânico é o fumo. Estou feliz, pois além do preço ser $60 \%$ a mais que o normal, faço umas 10 arrobas por mil pés (E9).

Entre os seis tipos de objetivos que induzem às mudanças dentro das organizações estão: melhorar o volume de vendas e serviços e aumentar a rentabilidade (JUDSON, 1976). Quando questionados sobre os motivos que levaram a mudar o sistema produtivo e as vantagens encontradas durante o processo de mudança do sistema produtivo, a renda não se destacou entre os relatos, porém estava entre as mais citadas em ambas. Esse resultado demonstra que, além dos cuidados com a saúde, ter benefícios econômicos, por meio de um preço de venda mais elevado dos produtos, também é um dos objetivos da transição agroecológica.

Meulenberg e Viaene (2005) afirmam que as estratégias de diferenciação têm em vista a multiplicidade de atributos dos alimentos que podem ser explorados para 
atender o consumidor. Agregar valor aos produtos alimentares e atender segmentos de consumidores com necessidades e comportamentos semelhantes são as duas faces da mesma estratégia. Nese caso, preservar a saúde e obter uma renda maior para a família podem ser consideradas as faces da estratégia.

O ponto crucial da tomada de decisão em grupo é lidar com as discrepâncias ao combinar preferências dos membros (HUANG, 2013). Alguns cooperados estão mais engajados do que outros e estão mais bem situados para participar, efetivamente, na decisão coletiva (CHADDAD; ILIOPOULOS, 2013). Para Almeida et al. (2014) falta, no âmbito institucional, um olhar multidimensional nas políticas públicas desenvolvidas que possam contribuir para o avanço do processo de transição agroecológica. Para que haja esse avanço na construção da agroecologia deve existir uma relação mais próxima entre as organizações de ensino, pesquisa e extensão. Sendo assim, seguem algumas percepções gerais que demostram de forma positiva o processo de transação dos cooperados (Quadro 8).

Quadro 8. Algumas percepções gerais sobre a transição agroecológica de sócios de cooperativa agropecuária em Boqueirão do Leão, Rio Grande do Sul

Positiva (E14).

É boa e todos têm que ajudar a planeta (E27).

Todos concordaram em mudar e devem estar gostando (E11).

Muitos têm vontade de plantar, dá mais trabalho no cultivo, mas vale a pena (E33).

Tem que pensar bem, porque dá mais trabalho e manejo do solo. O importante é que protege o ambiente (E5).

Nem todos produzem alimento orgânico ainda, mas o avanço está grande. Quem começa obtém vantagem logo e envolve toda a comunidade (E39).

Acho boa, mas todos têm que se ajudar (E8).

Quer certificar toda a propriedade pela Ecocert, mas é muito caro (E5).

Uma fumageira fez proposta para testar tabaco orgânico, vou fazer a experiência (E4).

Quando conseguir a certificação a responsabilidade aumenta. Ninguém pode fazer errado. O problema está no isolamento das áreas. Os vizinhos usam muito agrotóxico (E 13).

Os cooperados deviam ser selecionados. Somente os que têm interesse em ajudar a Cooperativa (E30).

Agora existe a comissão de qualidade na Cooperativa. Essa comissão visitará todas as propriedades para verificar os métodos e padrões dos agricultores (E33).

Jogaram um balde de água fria, no início era melhor. Depois da mudança, o apoio do governo municipal foi zero (E22).
A transição agroecológica requer soluções específicas para cada região e propriedade, considerando que cada agroecossistema e cada agricultor possuem características particulares (LIMA et al., 2014), porém, é preciso refletir antes de agir. Kotter (1999) relata que o sucesso da mudança depende do cumprimento de todas as fases. Diante das transformações e das novas tendências verificadas no ambiente externo, as mudanças devem ser contínuas na organização (JACOBSEN; RODRIGUES, 2002).

\section{CONCLUSÕES}

As novas práticas de manejo adotadas na transição agroecológica modificam a rotina de trabalho dos agricultores e exigem acompanhamento constante. Os agricultores concordam que para a transição agroecológica ter sucesso é preciso adquirir conhecimento. A comunicação é imprescindível para a mudança. Os fatores saúde e renda foram determinantes para a transição agroecológica, pois foram os mais citados nas percepções dos cooperados.

Alguns agricultores demonstraram desestímulo. Relatou-se que a falta de apoio do governo municipal e o fato de propriedades adjacentes usarem agrotóxicos prejudicam o processo transitório. Mesmo assim, eles relataram ter consciência de que devem ajudar uns aos outros e que toda a mudança é lenta. Apesar de algumas insatisfações, os cooperados admitem que essa transição é a melhor solução para alcançar os objetivos de cada um e, consequentemente, da Cooperativa.

\section{REFERÊNCIAS}

ALMEIDA, A. C. O.; PINHEIRO, R. C. S.; SANTOS, A. S. Concepções e iniciativas agroecológicas no estado de Sergipe. Revista Brasileira de Agroecologia, v. 9, n. 1, p. 158-169, 2014.

ALVES, E. Embrapa: a successful case of institutional innovation. In: MARTHA JUNIOR, G. B.; FERREIRA FILHO, J. B. de S. (Ed.). Brazilian agriculture development and changes. Brasília: Embrapa, 2012, p. 143-160.

ALVES, Z. M. M. B.; SILVA, M. H. G. F. D. da. Análise qualitativa de dados de entrevista: uma proposta. Paidéia, Ribeirão Preto, n. 2, 1992.

AZEVEDO, E.; SCHMIDT, W.; KARAM, K. F. Agricultura familiar orgânica e qualidade de vida. Um estudo de caso em Santa Rosa de Lima, SC, Brasil. Revista Brasileira de Agroecologia, Porto Alegre, v. 6, n. 3, p. 81-106, 2011.

BARDIN, L. Análise de Conteúdo. São Paulo: Edições 70, 2011. 118p.

BEGNIS, H. S. M.; AREND, S. C.; ESTIVALETE, V. F. B. Em frente ao espelho: a produção do conhecimento em cooperativas na Revista de Economia e Sociologia Rural. Revista de Economia e Sociologia Rural, Piracicaba, São Paulo, v. 52, n. 1, p. 099-116, 2014.

BUTTENBENDER, P. L. O Agronegócio Cooperativo. In: SPAREMBERGER, A.; BUTTENBENDER, P. L.; 
ZAMBERLAN, L. (Org.). Princípios de Agronegócios: conceitos e estudos de casos. Ijuí: Unijuí, 2010, p. 71-98.

CHADDAD, F.; ILIOPOUlOS, C.. Control Rights, Governance, and the Costs of Ownership in Agricultural Cooperatives. Agribusiness, Boston, v. 29, n. 1, p. 3-22, 2013.

COSTA, B. A. L.; AMORIM JÚNIOR, P. C. G.; SILVA, M. G. As Cooperativas de Agricultura Familiar e o Mercado de Compras Governamentais em Minas Gerais. Revista de Economia e Sociologia Rural, Piracicaba, São Paulo, v. 53, n. 1, p. 109-126, 2015.

DORNELLES, G. S. METAGESTÃO: a arte do diálogo nas organizações. São Paulo: Saraiva, 2006. 208p.

FERREIRA, P. R.; AMODEO, N. B. P. O SESCOOP e a criação do campo da educação cooperativista: organização do quadro social e educação cooperativista. In: Encontro de Pesquisadores Latino-americanos de Cooperativismo, 5, 2008, Ribeirão Preto/SP. Disponível em: <http://www.fundace.org.br/cooperativismo/arquivos_pesquis a_ica_la_2008/151-ferreira.pdf>. Acesso em: 25 nov. 2012.

FEE. FUNDAÇÃO DE ECONOMIA E ESTATÍSTICA. Resumo Estatístico do Município de Boqueirão do Leão. 2011. Disponível em: < http://www.fee.tche.br/sitefee/pt/content/resumo/pg_municipi os_detalhe.php?municipio=Boqueir $\% \mathrm{E} 3 \mathrm{o}+\mathrm{do}+\mathrm{Le} \% \mathrm{E} 3 \mathrm{o}>$.

Acesso em: 5 abr. 2013.

HUANG, T. C. K. A novel group ranking model for revealing sequence and quantity knowledge. European Journal of Operational Research, Amsterdam, v. 231, n. 3, p. 654-666, 2013.

IBGE. INSTITUTO BRASILEIRO DE GEOGRAFIA E ESTATÍSTICA. Cidades. 2010. Disponível em: http://www.ibge.gov.br/cidadesat/painel/painel.php?codmun= 430245. Acesso em: 05 abr. 2013.

JACOBSEN, A. L.; RODRIGUES, M. M. B. Abordagens para lidar com a resistência humana frente a processos de mudança organizacional. Revista de Ciências da Administração, Florianópolis, v. 14, n. 6, p. 39-49, 2002.

JESUS, P. P.; SILVA, J. S.; MARTINS, J. P.; RIBEIRO, D. D.; ASSUNÇÃO, H. F.. Transição Agroecológica na Agricultura Familiar: relato de experiência em Goiás e Distrito Federal. CAMPO-TERRITÓRIO: Revista de Geografia Agrária, v. 6, n. 11, p. 363-375, 2011.

JUDSON, A. S. Relações Humanas e Mudanças Organizacionais. São Paulo: Atlas, 1976. 244p.

KOTTER, J. P. Liderando a Mudança: Por que fracassam as tentativas de transformação. In: Harvard Business Review. Mudança. 2 ed. Rio de Janeiro: Campus, p. 9-26, 1999.

LAUDON, K. C.; LAUDON, J. P. Management information systems: managing the digital firm. 10 ed. New Jersey: Prentice Hall Inc. 2007.
LIMA, F. A. X.; PIRES, M. L. L. S.; VARGAS L. P. Do Convencional ao Agroecológico: a experiência de Santa Cruz da Baixa Verde - Sertão de Pernambuco. Revista Brasileira de Agroecologia, v. 9, n. 3, p. 03-20, 2014.

MARTINS, M. S. F. A Sensação, A Percepção e as Desordens da Percepção. 2011. Disponível em: <https://psicologado.com/neuropsicologia/a-sensacao-apercepcao-e-as-desordens-da-percepcao $>$. Acesso em: 04 abr 2016.

MEULENBERG, M. T. G.; VIAENE, J. Changing agri-food systems in Western countries: a marketing approach. In: JONGEN, W. M. F.; MEULENBERG, M. T. G. (Ed.). Innovation in the Production Systems - Product quality and consumer acceptance. Wageningen: Wageningen Pers, p. 17$56,2005$.

MOTA, J. C.; ALMEIDA, M. M.; MOTA, M. S.; MOTA, M. S.; ALENCAR, V. C. Estudo da complexidade ambiental visando o conhecimento interdisciplinar dos saberes e da educação ambiental. Revista Verde de Agroecologia e Desenvolvimento Sustentável, Pombal, v. 9, n. 5, p. 07-11, 2014.

PINHO, D. B. Doutrina Cooperativista e Desenvolvimento Econômico. São Paulo: Secretaria da Agricultura Departamento de Assistência ao Cooperativismo, 1967. 46p.

RODRIGUES, R. M. Pesquisa Acadêmica: como facilitar o processo de preparação de suas etapas. São Paulo: Atlas, 2007. 162p.

SCHNEIDER, J. O. (Org.) Educação Cooperativa e suas práticas. São Leopoldo: Editora Unisinos, 2003. 256p.

UNIVERSIDADE FEDERAL DO PARANÁ. Estatística II: notas de aula. Curitiba: UFPR, 2009. Disponível em: <http://www.est.ufpr.br/ce003/material/apostilace003.pdf>. Acesso em: 2 jan. 2014.

VALENT, V. D. Conceitos de Gestão da Inovação: compatibilidades da linguagem técnica na produção científica veiculada em periódicos brasileiros entre 2008 e 2012. Porto Alegre: UFRGS, 2013. 102p. 